\title{
"This perfume makes me sick, but I like it." Representative survey on health effects associated with fragrances
}

\author{
Ursula Klaschka* ${ }^{*}$
}

\begin{abstract}
Background: Fragranced consumer products—such as cleaning supplies, laundry products, perfumes, and air fresheners - have been associated with adverse effects on personal health and with subsequent societal effects. This study investigates self-reported effects associated with exposures to fragranced consumer products in Germany. Using a nationally representative population-based sample $(n=1102)$, data were collected in March 2019 using an online survey of adults in Germany. Special questions allowed to differentiate the answers given by various vulnerable subgroups of the general population with the intention to better understand their specific situations.

Results: One out of five persons (19.9\%) indicates to be fragrance-sensitive. More than half of these persons (55.3\%) report respiratory problems and more than a third of them (35.6\%) declare mucosal problems. Three out of four autists report to be fragrance-sensitive. Half of the general population (55.6\%) think of products with natural fragrance ingredients to be healthier than products with synthetic fragrance ingredients and do not know that this is a wrong assumption. Even more people who report adverse health effects have this wrong impression. People who describe negative health effects caused by fragrances indicate to be exposed by their own use to a similar or even higher extent (up to 98.6\%) compared to the general population (96.9\%). Slightly more men say that they read the references to the products to get information about the fragrance ingredients compared to women. Three quarters of the population use fragrances to feel more attractive, but still 7.6\% report respiratory problems when exposed to fragrances.

Conclusions: The high number of individuals who report to experience health problems upon exposure to fragranced products needs to be taken serious and further actions are urgent. Present risk communication measures do not seem to be sufficient to induce appropriate risk reduction behavior in affected persons.
\end{abstract}

Keywords: Fragrance, Fragranced consumer product, Indoor air quality, Labeling, Risk communication

\section{Background}

Fragrance compounds are present in a multitude of household products, even if they are not disclosed [1]. It has been known for a long time that several fragrance ingredients have negative effects on the human health or the environment [2]. The increasing knowledge led to several legal restrictions of various fragrance ingredients which are forbidden or may be used at lower thresholds

*Correspondence: klaschka@hs-ulm.de

University of Applied Sciences, Prittwitzstraße 10, 89075 Ulm, Germany for direct application in cosmetic products today, e.g., according to the Cosmetic regulation in Europe [3]. Nevertheless, the number of people who report various adverse health effects is high. Previous nationally representative surveys in the USA [4], Australia [5], the UK [6], and Sweden [7] found that 34.7\%, 33.0\%, 28.7\%, and $33.1 \%$ of the population, respectively, reported one or more types of adverse health effects from exposure to fragranced products.

These international results were the stimulus to add some further questions in the most recent nationally 
representative survey conducted in Germany to learn more about the individuals who describe health effects due to exposure to fragrance substances. The intention was to find out whether there are differences between the general public and vulnerable persons, e.g., people reporting asthma or being fragrance-sensitive. When do these people use fragranced products? What do they know about fragrances in products? Do they show special behavior to avoid fragrances and thus to minimize risks? What are their attitudes versus fragrances in their surroundings?

My hypotheses led me to the following questions: Are dermal effects induced by fragrances in personal care products the most frequently reported effects? Do persons who prefer fragrance-free products have considerably less fragrance-induced health effects? Do especially younger persons and women of all ages read the references on products to learn more about fragrance ingredients? Do people who read references, read them because they are fragrance-sensitive? Are people who read the references and people who observe health effects due to fragrances better informed about the chemistry and the legal provisions of fragrances? Do people, who consider products with natural fragrance ingredients as healthier, assume that these products would not emit hazardous air pollutants? Do people who read references, people who prefer fragrance-free products and people who are fragrance-sensitive or experience any other health effect reduce their exposure to fragrances?

\section{Methods}

The survey was conducted as described in Steinemann and Klaschka [8]. Using a random sample representative of age, gender, and region $(n=1102$; confidence limit $=95 \%$, margin of error $=3 \%$ ), an online survey was conducted of the adult population (ages 18-65) in Germany. The survey was run in the language of German.

The process of survey translation and implementation was performed by Survey Sampling International (SSI), a global survey research company and online panel provider.

For details on panel development, participant recruitment, survey design, and implementation, see Additional files 1 and 2. The survey completion rate was $83 \%$, and all responses were anonymous. Survey questions investigated the following areas: fragranced product use and exposure; health effects associated with exposure to fragranced products; specific exposure situations; effects of fragranced product exposure in the workplace and in society; preferences for fragrance-free environments and policies; and demographic information.

The following questions were added for the first time to the questionnaire that had been used in previous national surveys [4-7]: "Do you use perfumed products, such as perfume or deodorant, to make yourself feel more attractive?" "Do you consider people who use perfumed personal care products more attractive than people who do not?" "Do you consider people who use perfumed personal care products more hygiene-conscious than people who do not?" "Do you prefer that your clothes smell of fragrances after washing or that they do not smell after washing (no added perfume or no added odor)?" "Do you read the references to the products you use to get information about the fragrances it contains?" "Does the information about a particular fragrance ingredient in a product affect your purchasing decision?" "Do you believe that products with natural fragrance ingredients are healthier than products with synthetic fragrance ingredients?" "Do you prefer fragrance-free products when they are available?"

"Fragrance-sensitive persons" were defined here as persons who reported one or more types of adverse health effects from exposure to one or more types of fragranced products.

"Autists" were defined here as persons who answered yes to the following question: 'Has a doctor or health care professional ever told you that you have autism or autism spectrum disorder?' Autists deserve special attention in this study as there is strong evidence that autistic individuals are affected more than other vulnerable groups by exposure to fragranced consumer products [9]. As the number of autists is too small for a statistical evaluation in this study, I include the absolute numbers in the text.

"Asthmatics" were defined here as persons who answered yes to the following question: 'Has a doctor or health care professional ever told you that you have asthma or an asthma-like condition?'

For the evaluation, I identified "subgroups" of people who answered "yes" to a specific question in the survey, e.g., all people who preferred fragrance-free products, all persons who used fragrances to feel more attractive, or all persons who indicated to read the references to learn more about the fragrances in a certain product.

It must be noticed that the subgroups may overlap: E.g., around a third (31.4\%) of people who read references to the products to get information about the fragrance ingredients and nearly half (44\%) of the asthmatics were fragrance-sensitive. Or as another example, there were 23 autists among the individuals who used fragrances to make themselves feel more attractive.

Limitations of the study included the following: (a) It was not feasible to mention all possible product types and health effects. However, the low percentages for responses in the "other" category indicated that the survey captured the primary products and effects. (b) Long-term health effects as well as health effects, which 
consumers could not link directly with the exposure to fragranced products, could not be considered here. (c) Data were based on self-reported data. This is the nature of the standard method of a survey. (d) The cross-sectional design of the study, which is useful for determining prevalence, is limited in the ability to determine temporal relationships and trends. (e) The survey focused on adults aged 18-65, which excluded data on effects of fragranced consumer products on children and the elderly, but allowed to obtain a picture of adult persons who may be in contact with fragranced products from their private use in addition to their workplaces. Children as especially vulnerable group of the population were not considered, because they would not be able to answer the questionnaire themselves. (f) Questions about exposure to various household products did not comprise information about the amounts applied, as it was not the purpose here to make a quantitative analysis of exposure. (g) It is the nature of a survey that it did not cover non-conscious health effects of scent. (h) The focus on fragrances and the detailed list of health effects in this survey might have led survey participants into temptation to relate their health effects to fragrances, where there might not have been any link. (i) On the other hand, prolonged high concentrations of perfumes in the breathing air reduce the ability to sense the odors due to olfactory adaptation. These persons might experience health effects due to fragrances, but cannot relate them to fragrance exposure because they do not perceive the odor.

\section{Results and discussion}

\section{Health effects: respiratory and mucosal problems are predominant}

This survey is the first study of this kind that was conducted in Germany [8]. It addresses the multitude of potential health effects and gives a representative survey of the general German population. So far, in Germany, studies on health effects caused by fragrances focused on skin effects (sensitization and contact allergy), and they concentrated on cosmetic products or washing and cleaning products. In a survey conducted in Germany in 2010, a third of the German population indicated to observe health problems when using personal care products and named mainly allergic reactions and skin irritations when asked about health effects caused by chemicals [10]. Furthermore, previous studies considered mainly the 26 allergenic fragrance ingredients that have to be listed in the ingredient lists of cosmetics according to the European legislation [3,11-15], although it has been known for a long time that there are also further fragrance compounds in use which are potent allergens (e.g., [16]). Many of the data raised in Germany so far derive from patch test populations of patients in dermatological hospitals and not from the general population. Many data were collected in the Information Network of Departments of Dermatology in Göttingen, Germany, which is sponsored by the cosmetic and fragrance industry (https ://www.ivdk.org/en/) [13]. This focus in the previous studies in Germany might be due to the current legislation, as the EU-Cosmetics regulation [3] asks for a 'cosmetic product safety report', which should include the 'Toxicological profile of the substances... for all relevant toxicological endpoints. A particular focus on local toxicity evaluation (skin and eye irritation), skin sensitization, and in the case of UV absorption photo-induced toxicity shall be made.' These local dermal effects are the only ones that are named in the EU Regulation Annex I Part 1 for the cosmetic product safety report. All further effects are summarized as 'Undesirable effects and serious undesirable effects.' The classification and labeling of fragrance ingredients [17] show that many fragrance compounds are hazardous substances classified due to various toxicological and ecotoxicological hazards and do not only have effects on the skin, but some are, e.g., harmful if swallowed (R22, new H302), irritating to respiratory system (R37, new H334), or harmful by inhalation, in contact with skin and if swallowed (R20/21/22, new H302/H312/ H332) [12].

Self-reported health effects are divers and frequent. In the present study, respiratory problems are the predominant health effect associated with fragranced products indicated in the general population (11.0\%) as well as in all subgroups $(7.6-55.3 \%)$, followed by mucosal problems (5.9-35.6\%), dermal problems $(4.8-34.7 \%)$, neurological problems $(4.1-30.6 \%)$, and migraine headaches (4.0-25.1\%). All these health effects are reported by at least $5 \%$ of the general population. This sequence is similar for the general population and all subgroups, apart from the persons who indicate to be autists. More people who prefer fragrance-free products and more people who read the references report cardiovascular problems (5.2\% resp. 6.7\%) associated with fragrance use than asthma attacks (4.8\% resp. $5.4 \%$ ). In all other subgroups and in the general population, this is the other way round (Table 1). More than half of the individuals who are fragrance-sensitive $(55.3 \%)$ report inhalation problems, and around a third of them declare mucosal problems (35.6\%) or dermal problems $(32.0 \%)$ when exposed to fragrances. More than a quarter of persons who are fragrance-sensitive indicate to have neurological problems (27.4\%) or migraine headaches $(25.1 \%)$ under such conditions. Nearly a tenth $(9.6 \%)$ of the fragrance-sensitive persons indicate to have musculoskeletal problems when exposed to fragrances. Every tenth (10.0\%) of persons who prefer fragrance-free products declare to have skin problems due to fragrance exposure. Twice as many people 
Table 1 Self-reported health effects associated with fragranced products

\begin{tabular}{|c|c|c|c|c|c|c|c|c|}
\hline \multirow[t]{2}{*}{ Health effects } & \multirow{2}{*}{$\begin{array}{l}\text { General } \\
\text { population }\end{array}$} & \multicolumn{7}{|l|}{ Subgroups } \\
\hline & & $\begin{array}{l}\text { People who } \\
\text { use fragrances } \\
\text { to feel more } \\
\text { attractive }\end{array}$ & $\begin{array}{l}\text { People who } \\
\text { consider natural } \\
\text { ingredients } \\
\text { healthier }\end{array}$ & $\begin{array}{l}\text { People } \\
\text { who prefer } \\
\text { fragrance-free } \\
\text { products }\end{array}$ & $\begin{array}{l}\text { People } \\
\text { who read } \\
\text { the references }\end{array}$ & Asthmatics & $\begin{array}{l}\text { Fragrance- } \\
\text { sensitive } \\
\text { people }\end{array}$ & Autists \\
\hline $\begin{array}{l}\text { Size of (sub) } \\
\text { group }\end{array}$ & 1102 & 799 & 613 & 458 & 312 & 225 & 219 & 49 \\
\hline $\begin{array}{r}\text { Respiratory } \\
\text { problems }\end{array}$ & 11.0 & 7.6 & 11.9 & 17.7 & 19.2 & 24.4 & 55.3 & 30.6 \\
\hline $\begin{array}{l}\text { Mucosal prob- } \\
\text { lems }\end{array}$ & 7.1 & 5.9 & 8.2 & 12.4 & 14.1 & 14.2 & 35.6 & 28.6 \\
\hline Skin problems & 6.4 & 4.8 & 7.7 & 10.0 & 12.8 & 16.0 & 32.0 & 34.7 \\
\hline $\begin{array}{l}\text { Neurological } \\
\text { problems }\end{array}$ & 5.4 & 4.1 & 6.5 & 9.0 & 9.9 & 11.1 & 27.4 & 30.6 \\
\hline $\begin{array}{l}\text { Migraine head- } \\
\text { aches }\end{array}$ & 5.0 & 4.0 & 5.7 & 8.1 & 8.7 & 12.0 & 25.1 & 22.4 \\
\hline $\begin{array}{l}\text { Gastrointestinal } \\
\text { problems }\end{array}$ & 4.4 & 3.0 & 5.2 & 7.9 & 8.0 & 10.2 & 21.9 & 24.5 \\
\hline $\begin{array}{l}\text { Cognitive prob- } \\
\text { lems }\end{array}$ & 3.7 & 2.8 & 4.6 & 5.5 & 7.1 & 12.4 & 18.7 & 28.6 \\
\hline Asthma attacks & 3.4 & 2.6 & 3.1 & 4.8 & 5.4 & 13.8 & 16.9 & 20.4 \\
\hline $\begin{array}{l}\text { Cardiovascular } \\
\text { problems }\end{array}$ & 2.9 & 2.1 & 3.6 & 5.2 & 6.7 & 8.0 & 14.6 & 28.6 \\
\hline $\begin{array}{l}\text { Immune system } \\
\text { problems }\end{array}$ & 2.6 & 2.1 & 3.8 & 3.7 & 5.4 & 9.3 & 13.2 & 38.8 \\
\hline $\begin{array}{l}\text { Musculoskeletal } \\
\text { problems }\end{array}$ & 1.9 & 1.6 & 1.3 & 2.8 & 3.2 & 6.7 & 9.6 & 24.5 \\
\hline Other & 0.6 & 0.8 & 0.5 & 0.9 & 1.0 & 1.3 & 3.2 & 0 \\
\hline
\end{tabular}

Percentage of answers given by the general population and by the various subgroups to the questions about health effects associated with fragranced products. The numbers of the persons in the respective subgroups are given in the first line

who read the references $(8.0 \%)$ compared to the general population $(4.4 \%)$ report gastrointestinal problems in such cases. One out of eight asthmatics (12.4\%) reports cognitive problems when exposed to fragrances. Asthma attacks caused by fragrances were reported by $13.8 \%$ of asthmatics. Nearly a tenth $(9.3 \%)$ of asthmatics report immune system problems caused by fragrances. Cardiovascular problems are reported by up to $28.6 \%$ in the subgroups due to fragrance exposure.

In all but one subgroup, the percentage of persons who report health effects are higher than in the general population, while slightly less people who use fragrances to feel more attractive indicate to have health effects caused by fragrances compared to the general population.

The health effects reported depend on the source of the fragrance: For all but one exposure source, inhalation problems are the most frequent effects named. The scent of laundry is the only exposure path where the predominant health problems observed are dermal problems (30.7\%), not respiratory problems (24.0\%).

It is important to note that the subgroups are not equally composed of all age classes. There are two evident cases: for example, relatively more young men indicate to be fragrance-sensitive (Fig. 1).

Furthermore, twice as many women in the age class 45-54 (20.0\%) indicate to be asthmatics compared to men (10.6\%), while there is no further pronounced dependency on age and gender (Fig. 2).

Asthma or asthma like conditions, fragrance-sensitivity and allergy or unusual sensitivity are frequently reported health conditions in the general population and in all subgroups (Table 2).

Autists indicate very frequently serious health effects. More than three quarters (40 out of 49 autists, $81.6 \%$ ) declare to be fragrance-sensitive, while 39 (79.6\%) in this subgroup declare to have asthma. Every second, autist ( 28 out of $49,57.1 \%$ ) reports a total or partial loss of bodily or mental functions due to the exposure to fragrances. Also, every second, autist (26 out of 49,53.1\%) indicates multiple chemical sensitivities.

Nearly half of the fragrance-sensitive persons (45.2\%) declare to be diagnosed with asthma. Nearly a third (29.9\%) of people who prefer fragrance-free products belong to the fragrance-sensitive group. A third (31.4\%) 


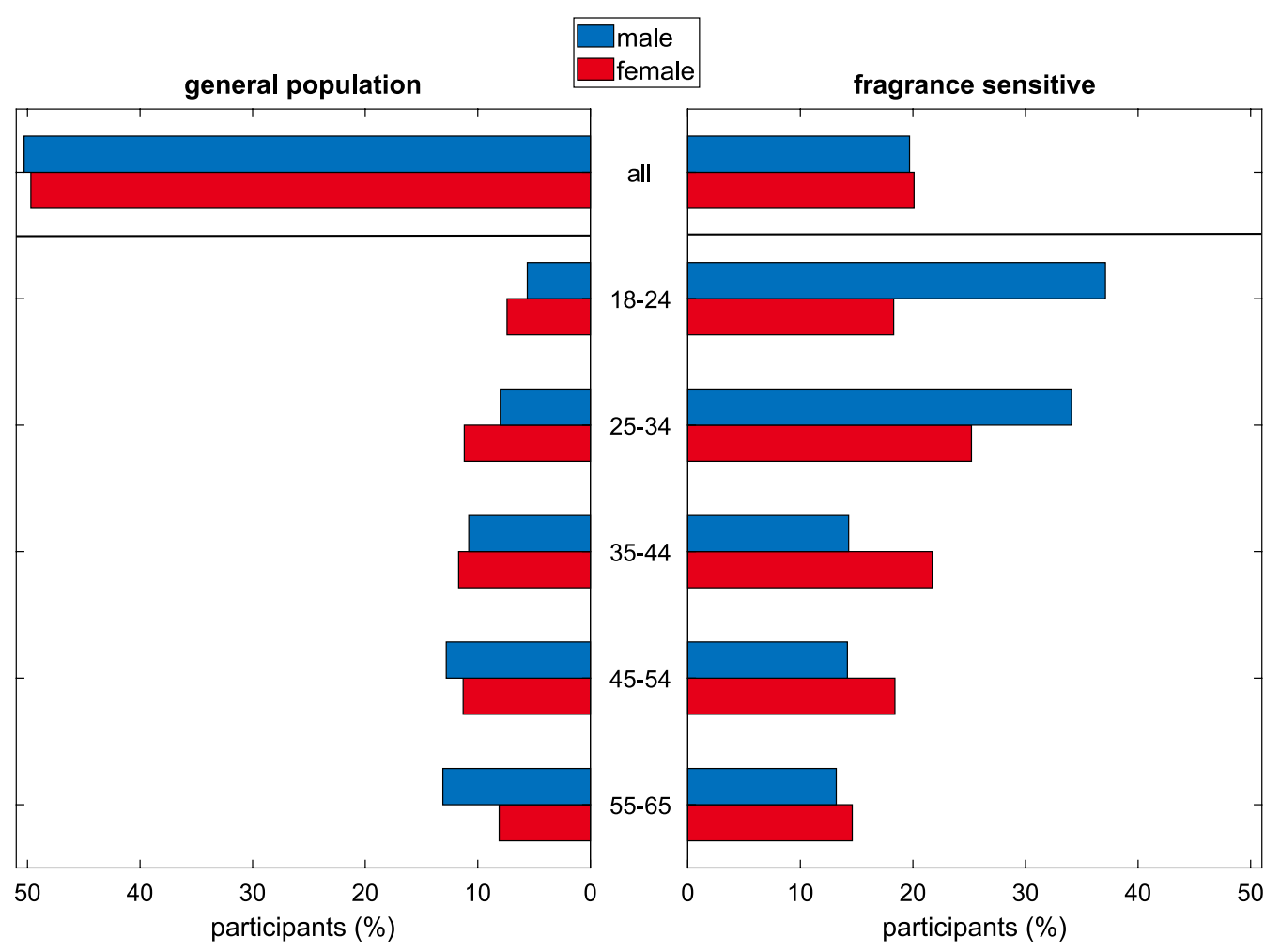

Fig. 1 Proportions of men and women in the respective age classes. Percentages of male and female participants in the general population (left) and in the subgroup who indicate to be fragrance-sensitive (right)

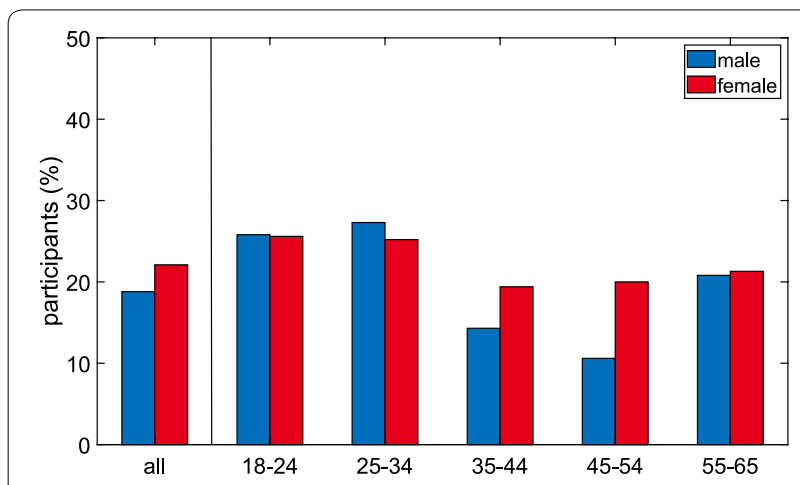

Fig. 2 Proportions of asthmatic men and women. Percentages of female and male participants who indicate to be asthmatics in the respective age-classes

of people who read the references to the products to get information about the fragrance ingredients report to be fragrance-sensitive, and a quarter $(27.6 \%)$ of these people indicate to be allergic or unusually sensitive. One out of eight persons (12.6\%) who use perfumed products to make them feel more attractive compared to the general population (16.1\%) considers themselves as allergic or unusually sensitive. Like in Table 1, data in Table 2 show that less people who use perfumed products to make themselves feel more attractive compared to the general population declare to have the health problems in question. All the other subgroups report the respective health effect more frequently compared to the general population.

These findings have the following implications:

Autists, asthmatics, and fragrance-sensitive persons experience adverse health effects in response to fragrance exposure clearly more often than the average.

In accordance with the research focus on dermal effects caused by fragrances in Germany in the last decades (see above), my hypothesis was that dermal effects caused by fragrances in personal care products would be reported most frequently, but this is not the case. Inhalation problems are the predominant health effects reported in the general population as well as in all subgroups (apart from autists, where immune system problems are the most frequently indicated effects). Dermal effects are only indicated most frequently by survey participants when exposed from dryer vents.

Another hypothesis of mine was that people who use fragranced products to make themselves feel more attractive would not have any health problems, because 
Table 2 Self-reported health conditions

\begin{tabular}{|c|c|c|c|c|c|c|c|c|}
\hline Health condition & $\begin{array}{l}\text { General } \\
\text { population }\end{array}$ & $\begin{array}{l}\text { People who } \\
\text { use fragrances } \\
\text { to feel more } \\
\text { attractive }\end{array}$ & $\begin{array}{l}\text { People who } \\
\text { consider natural } \\
\text { ingredients } \\
\text { healthier }\end{array}$ & $\begin{array}{l}\text { People who } \\
\text { prefer fragrance- } \\
\text { free product }\end{array}$ & $\begin{array}{l}\text { People } \\
\text { who read } \\
\text { references }\end{array}$ & Asthmatics & $\begin{array}{l}\text { Fragrance- } \\
\text { sensitive } \\
\text { people }\end{array}$ & Autists \\
\hline $\begin{array}{l}\text { Asthma or } \\
\text { asthma-like } \\
\text { condition }\end{array}$ & 21.4 & 19.0 & 21.5 & 23.1 & 24.7 & 100.0 & 45.2 & 79.6 \\
\hline $\begin{array}{l}\text { Fragrance-sen- } \\
\text { sitive }\end{array}$ & 19.9 & 15.0 & 21.4 & 29.9 & 31.4 & 44.0 & 100.0 & 81.6 \\
\hline $\begin{array}{l}\text { Allergic or unusu- } \\
\text { ally sensitive }\end{array}$ & 16.1 & 12.6 & 18.8 & 25.8 & 27.6 & 40.0 & 53.4 & 55.1 \\
\hline $\begin{array}{l}\text { Multiple chemical } \\
\text { sensitivities }\end{array}$ & 7.6 & 5.6 & 9.5 & 10.3 & 15.7 & 22.7 & 27.9 & 53.1 \\
\hline $\begin{array}{l}\text { Total or partial } \\
\text { loss of bodily } \\
\text { or mental func- } \\
\text { tions due to } \\
\text { the exposure to } \\
\text { fragrances }\end{array}$ & 6.7 & 5.1 & 8.2 & 11.1 & 14.1 & 21.3 & 33.8 & 57.1 \\
\hline $\begin{array}{l}\text { Autism spectrum } \\
\text { disorder }\end{array}$ & 2.8 & 2.0 & 2.6 & 3.3 & 4.5 & 11.1 & 11.0 & 63.3 \\
\hline Autism & 1.9 & 1.3 & 2.4 & 2.2 & 3.2 & 7.1 & 8.7 & 42.9 \\
\hline
\end{tabular}

Percentage of persons who report respective health conditions (sizes of groups see Table 1)

I assumed that the experience of health effects would not make someone feel attractive and would lead to an avoidance of the fragranced products. However, the data show that only slightly less people in this subgroup indicate to experience health problems than the average, the percentage is still rather high. In all other subgroups, the percentage of persons who report health effects is higher than in the general population.

I expected that persons who prefer fragrance-free products would have considerably less fragrance-induced health effects, because I assumed that they would use less fragranced products and hence experience less health effects. However, even in this subgroup, more people describe health effects compared to the general population and even one out of ten describes a partial loss of bodily or mental functions due to the exposure to fragrances.

It was described that fragrance contact allergic patients read ingredient lists as a feasible strategy to find products which they can tolerate [18]. Therefore, a further hypothesis of mine was, that people who read references, read them because they are fragrance-sensitive; however, only less than a third of people who read references indicate to be fragrance-sensitive.

The present findings show that it is not sufficient to focus on skin effects caused by 26 potentially allergenic fragrance ingredients in personal care products, as it was done in most studies in the past in Germany. These former studies considered only a small fraction of hazards and did not mirror the multitude of potential health problems in consumers associated with the usage of fragranced consumer products.

The present data show clearly that skin effects (contact allergy, eczema, etc.) are observed, but respiratory and mucosal problems are even more frequently reported in the general population. Although the present study shows the multitude of effects, it can only catch the effects where the survey participants could make a causal link themselves between fragrance exposure and their personal well-being. This means that sub-chronic and long-term effects, indirect and subconscious effects (e.g., carcinogenicity, mutagenicity, endocrine disruption, effects on reproduction or other organ toxicity) would come on top of the effects described here. A broader approach for the safety assessment of fragrances was already described in 2003 [19], where data on acute, sub-chronic and chronic toxicity, mutagenicity, dermal irritation, skin sensitization photoirritation, photoallergy, developmental and reproductive toxicity, and carcinogenicity should be included.

In addition, the present study points out that not only cosmetic products should be considered as a source for fragrance exposure in indoor air, but also the big variety of other fragranced consumer products must be taken into account. It confirms the ubiquity of the fragrance compounds by the observation of the effects described by the study participants who are confronted with the 
aggregated exposure to the volatile compounds, that is the sum of various chemicals from various fragranced products (see also analytical measurements in various household products [1]). This aggregate exposure represents the relevant concentration of hazardous substances in the indoor air leading to health effects in consumers and should be considered in risk assessment calculations.

\section{Knowledge: wrong assumptions about fragrances are frequent}

How many people have basic knowledge about the chemistry of fragrance ingredients? five questions in the survey (Table 3 , column 1 ) address this aspect. Autists are by far the best informed: 33 out of 49 (67.3\%) are aware that a fragrance in a product is typically a chemical mixture, $20(40.8 \%)$ are aware that fragrance chemicals need not be fully disclosed on the product labels, $30(61.2 \%)$ are aware that fragrances in products emit hazardous air pollutants, and $21(42.9 \%)$ are aware that natural fragranced products also emit hazardous pollutants. In all subgroups

Table 3 Knowledge about fragrances

\begin{tabular}{|c|c|c|c|c|c|c|c|c|}
\hline Questions & $\begin{array}{l}\text { General } \\
\text { population }\end{array}$ & $\begin{array}{l}\text { People who } \\
\text { use fragrances } \\
\text { to feel more } \\
\text { attractive }\end{array}$ & $\begin{array}{l}\text { People who } \\
\text { consider natural } \\
\text { ingredients } \\
\text { healthier }\end{array}$ & $\begin{array}{l}\text { People who } \\
\text { prefer fragrance- } \\
\text { free products }\end{array}$ & $\begin{array}{l}\text { People } \\
\text { who read } \\
\text { references }\end{array}$ & Asthmatics & $\begin{array}{l}\text { Fragrance- } \\
\text { sensitive } \\
\text { people }\end{array}$ & Autists \\
\hline $\begin{array}{l}\text { Are you aware } \\
\text { that a fragrance } \\
\text { in a product is } \\
\text { typically a chem- } \\
\text { ical mixture of } \\
\text { several dozen to } \\
\text { several hundred } \\
\text { chemicals? }\end{array}$ & 40.2 & 37.5 & 42.4 & 47.4 & 53.2 & 47.6 & 48.4 & 67.3 \\
\hline $\begin{array}{l}\text { Are you aware } \\
\text { that fragrance } \\
\text { chemicals do } \\
\text { not need to be } \\
\text { fully disclosed } \\
\text { on the product } \\
\text { label or material } \\
\text { safety data } \\
\text { sheet? }\end{array}$ & 27.5 & 26.0 & 28.9 & 32.3 & 42.3 & 30.2 & 37.0 & 40.8 \\
\hline $\begin{array}{l}\text { Are you aware that } \\
\text { fragranced prod- } \\
\text { ucts typically } \\
\text { emit hazardous } \\
\text { air pollutants } \\
\text { such as formal- } \\
\text { dehyde? }\end{array}$ & 23.9 & 21.9 & 25.6 & 30.3 & 38.5 & 32.9 & 37.0 & 61.2 \\
\hline $\begin{array}{l}\text { Are you aware that } \\
\text { even so-called } \\
\text { natural, green, } \\
\text { and organic } \\
\text { fragranced prod- } \\
\text { ucts typically } \\
\text { emit hazardous } \\
\text { air pollutants? }\end{array}$ & 14.2 & 12.1 & 13.9 & 18.8 & 26.6 & 24.0 & 29.2 & 42.9 \\
\hline $\begin{array}{l}\text { Do you think of } \\
\text { products with } \\
\text { natural fragrance } \\
\text { ingredients to } \\
\text { be healthier } \\
\text { than products } \\
\text { with synthetic } \\
\text { fragrance ingre- } \\
\text { dients? }\end{array}$ & 55.6 & 58.6 & 100 & 69.2 & 67.3 & 58.7 & 59.8 & 59.2 \\
\hline
\end{tabular}

Percentage of "Yes" answers given by the general population and by the various subgroups (sizes of groups see Table 1) 
(with the exception of people who use fragrances to feel more attractive), more persons are aware of these basic facts compared to the general population.

People who read the references are best informed (42.3\%) about the fact that fragrance chemicals do not need to be fully disclosed on the product label or the material safety data sheet. More than half (53.2\%) of this group are aware that a fragrance in a product is typically a chemical mixture of several dozen to several hundred chemicals. Nearly a third (30.3\%) of people who prefer fragrance-free products are aware that fragranced products typically emit hazardous air pollutants. One out of seven (13.9\%), people who think of products with natural fragrance ingredients to be healthier, is aware that even so-called natural, green, and organic fragranced products typically emit hazardous air pollutants, a percentage that is very close to the average of $14.2 \%$. Nearly twice as many know this in the subgroup of people who read the references (26.6\%). Half of the general population (55.6\%) think of products with natural fragrance ingredients to be healthier than products with synthetic fragrance ingredients and do not know that this is a wrong assumption [20]. In all subgroups, even more people have this wrong impression (58.6\%-100\%). Two-thirds $(67.3 \%)$ of people who read references believe that products with natural fragrance ingredients are healthier than products with synthetic fragrance ingredients. In this case, a higher percentage of this subgroup give this wrong answer compared to the general population. This is also the case for people who prefer fragrance-free products, where $69.2 \%$ believe that products with natural fragrance ingredients are healthier (Table 2).

Slightly more women $(52.9 \%)$ consider products with natural fragrance ingredients healthier compared to men $(47.1 \%)$. This correlates with the general preference of natural products in the German population even if natural products are more expensive [10]. In this case, also slightly more women preferred natural products (67\%) compared to men (60\%) [10]. The demographic group with the lowest percentage of people who consider natural fragrance ingredients healthier were young men aged $18-24$ (4.4\%).

In total, more than a quarter $(28.3 \%)$ of the interviewees indicate to read the references to learn more about the fragrances in a certain product. Overall, more men, especially young men (age class 18-24), than women read the references (Fig. 3). This result can be seen as contrast to the results obtained in 2010 where young people (aged 14-29) were the group with the least interest in chemical risks compared to the other age classes [10].

Nearly three-fourths (72.5\%) of the German population use perfumed products to feel themselves more attractive, with a small difference between the male (48.1\%)

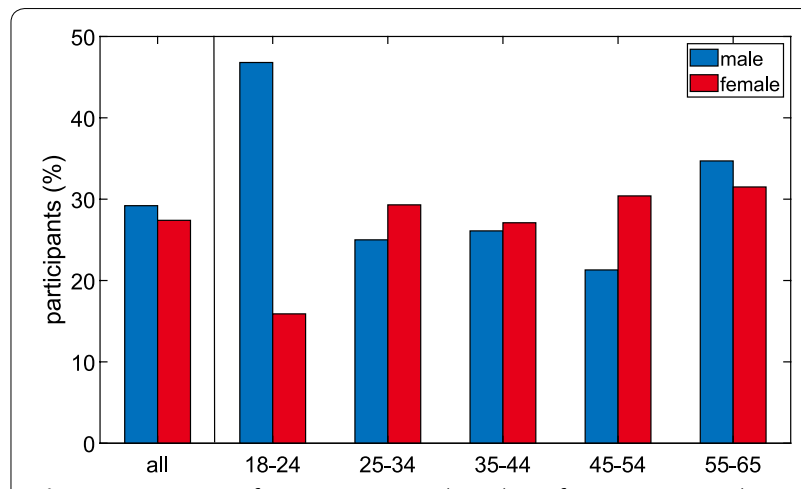

Fig. 3 Proportion of participants reading the references on products. Percentage of men and women in each age class who indicate to read the references to learn more about the fragrances in a certain product

and female $(51.9 \%)$ survey participants. Young women in the age class 18-24 are the demographic group with the highest frequency of perfume use with the purpose to feel more attractive (80.4\%). Most (83.0\%) persons who indicate that they use perfumed products to feel more attractive are exposed from their own perfume use. Still, $48.2 \%$ who do not use perfumed products to feel more attractive are exposed from their own perfume use.

These findings have the following implications:

One of my hypotheses was that people who observe health effects due to fragrances would be better informed about the chemistry and the legal provisions of fragrances. This was the case to some degree for the fragrance-sensitive persons and asthmatics, while autists have by far the best knowledge about fragrances compared to the other subgroups.

I expected that fragrance-sensitive persons and people who prefer fragrance-free products would be more aware of the toxicological impacts of fragrances and the legal provisions, but this was not as significant as expected.

Another hypothesis was that people who think of products with natural fragrance ingredients to be healthier would assume that so-called natural, green, and organic fragranced products would not emit hazardous air pollutants. This hypothesis builds on the finding that "natural" was associated with "healthy" by the majority of the German population (87\%) in a survey conducted in 2010 [10]. Interestingly, there are $13.9 \%$ in the subgroup who consider natural ingredients healthier, although they know that also natural, green, and organic fragranced products typically emit hazardous air pollutants. This is an example for cognitive dissonance where some consumers seem to have convictions, which are in contrast to their knowledge. 
A further hypothesis was that more women would read the references compared to men, but this was also not the case. Women are more concerned about the food they eat and more health conscious (e.g., [21]), but apparently not about fragrances in products. I had also expected that young people might be more cautious about fragranceuse than older generations and tend to read the references more frequently. But this was only true for young men aged 18-24. They are the age group with the highest percentage of fragrance-sensitive persons (Fig. 1) and they are also the age group with the highest percentage of people who read the references to the products to get information about the fragrance ingredients (Fig. 3).

Another hypothesis of mine was that most people who read the references would be better informed about the chemistry and the legal provisions of fragrances. I found that more people in this subgroup had the necessary knowledge, but the difference to the general population was not as big as expected. Two-thirds of people who read references believe that products with natural fragrance ingredients are healthier than products with synthetic fragrance ingredients, compared to $55.6 \%$ in the general population. This shows that reading references does not prohibit from wrong assumptions. One could have assumed that people who indicate to read the references unconsciously answer the other questions about knowledge in this survey more in favor of their conscious. However, this result shows that there is no obvious bias in the survey toward risk literacy by people who answered that they read the references.

To sum up: The knowledge about fragrance ingredients in the general population is rather low. Less than half of the population are aware that the words "fragrance" or "perfume" and the like can cover several hundred fragrance ingredients undisclosed. Only one out of seven persons knows that so-called natural, green, and organic fragranced products typically emit hazardous air pollutants. This moderate knowledge coincides with findings from other surveys where consumers' knowledge about chemicals in general was found to be minor [10].

\section{Exposure: people who report adverse health effects from fragrance compounds expose themselves to these substances}

Nearly every person (96.9\%) in Germany indicates to be exposed to fragrances from their own use at least once a week (Fig. 4), with the predominant sources being their personal care products (89.9\%). Slightly less people $(82.1 \%)$ indicate to be exposed from others' use at least once a week, with fragrances from perfumes $(65.1 \%)$ as

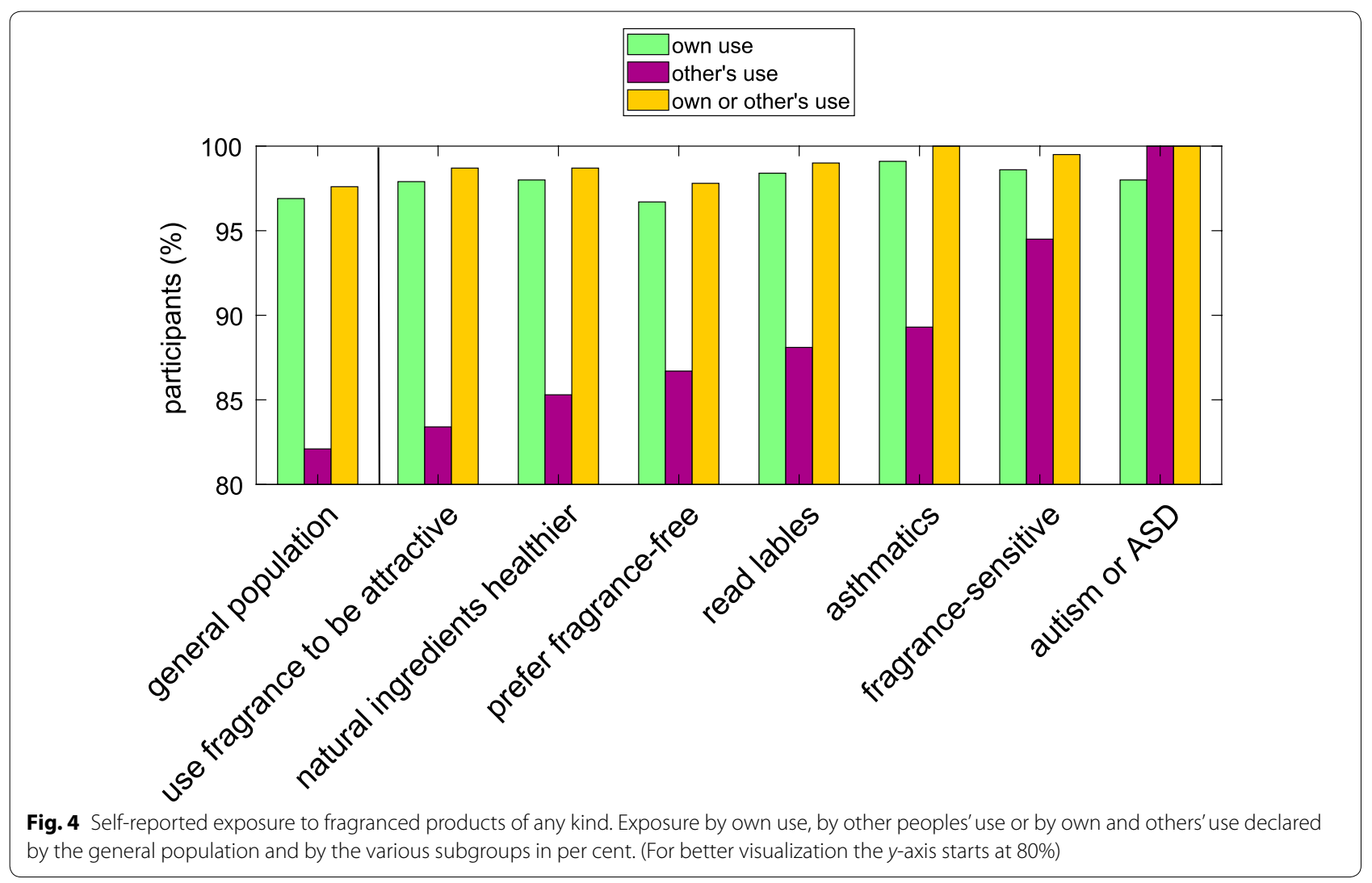


predominant source. In all subgroups, the self-reported exposure by own use is above $96 \%$, while the exposure by other peoples' use is above $83 \%$. All subgroups report higher exposure from own and others' use compared to the general population (Fig. 4).

The subgroup of people who prefer fragrance-free products indicate to be exposed slightly less to two product groups: $42.1 \%$ are exposed to fragrances from air fresheners and deodorizers by their own use (compared to $46.0 \%$ of the general population), $66.6 \%$ are exposed to perfumes by their own use (compared to $73.4 \%$ in the general population). There is no significant difference in the other product groups.

Nearly all persons who are fragrance-sensitive (98.6\%) indicate to be exposed to fragrances from their own use; this number is slightly higher compared to the general German population (96.9\%) (Fig. 4). The same is true for the exposure of persons who are fragrance-sensitive to fragrances from other persons' use (94.5\%) compared to the general population (82.1\%).

Nearly three-fourths (72.5\%) of the German population indicate to use fragrances to feel more attractive. In contrast to this result, it is interesting to note that every second person (48.2\%) declares to use perfume, although they indicate that they do not feel more attractive by fragranced products. Such unexpected answers indicate that a lot more details would be needed to understand the motivations of people to apply perfumes and to understand their comprehension of "feeling more attractive".

Table 4 compiles self-reported health effects under different exposure scenarios. Around one out of two autists indicates to experience health effects under the situations described. Health effects are most frequently described by all subgroups after a room has been cleaned with scented products $(9.0-59.8 \%)$. This implies that cleaning personal who is exposed to fragranced washing and cleaning products [11] for many hours each working day might be affected most [22]. Self-reported health effects are also frequent when being near a perfumed person (6.9-55.1\%). Exposure by air fresheners (7.3-47.5\%) and the scent from a dryer vent $(5.1-57.1 \%)$ is comparably less frequently responsible for self-reported health effects. This sequence is the same for all subgroups, apart from autists who describe more health effects from scented products coming from a dryer vent (28 out of $49,57.1 \%)$ than the other subgroups. Again, less persons who use fragrances to feel more attractive compared to the general population declare health effects under these

Table 4 Self-reported health problems under various situations in the house

\begin{tabular}{|c|c|c|c|c|c|c|c|c|}
\hline $\begin{array}{l}\text { Health effects } \\
\text { when... }\end{array}$ & $\begin{array}{l}\text { General } \\
\text { population }\end{array}$ & $\begin{array}{l}\text { People who } \\
\text { use fragrances } \\
\text { to feel more } \\
\text { attractive }\end{array}$ & $\begin{array}{l}\text { People who } \\
\text { consider natural } \\
\text { ingredients } \\
\text { healthier }\end{array}$ & $\begin{array}{l}\text { People who } \\
\text { prefer fragrance- } \\
\text { free products }\end{array}$ & $\begin{array}{l}\text { People } \\
\text { who read } \\
\text { references }\end{array}$ & Asthmatics & $\begin{array}{l}\text { Fragrance- } \\
\text { sensitive } \\
\text { people }\end{array}$ & Autists \\
\hline $\begin{array}{l}\text { Being in a room } \\
\text { after it has } \\
\text { been cleaned } \\
\text { with scented } \\
\text { products }\end{array}$ & 11.9 & 9.0 & 14.2 & 18.6 & 21.5 & 27.1 & 59.8 & 57.1 \\
\hline $\begin{array}{l}\text { Being near } \\
\text { someone who } \\
\text { is wearing a } \\
\text { fragranced } \\
\text { product }\end{array}$ & 10.2 & 6.9 & 11.4 & 17.2 & 18.6 & 24.4 & 51.1 & 55.1 \\
\hline $\begin{array}{l}\text { Exposed to air } \\
\text { fresheners or } \\
\text { deodorizer }\end{array}$ & 9.4 & 7.3 & 11.1 & 15.3 & 17.9 & 24.0 & 47.5 & 44.9 \\
\hline $\begin{array}{l}\text { Exposed to the } \\
\text { scent of laundry } \\
\text { products com- } \\
\text { ing from a dryer } \\
\text { vent }\end{array}$ & 6.8 & 5.1 & 8.5 & 9.6 & 13.1 & 17.8 & 34.2 & 57.1 \\
\hline $\begin{array}{l}\text { Exposed to } \\
\text { fragranced } \\
\text { products in } \\
\text { work environ- } \\
\text { ment caused } \\
\text { to become sick, } \\
\text { lose work days, } \\
\text { or lose a job }\end{array}$ & 5.5 & 4.0 & 5.9 & 9.4 & 11.9 & 14.7 & 22.4 & 44.9 \\
\hline
\end{tabular}

Percentage of answers given by the general population and the various subgroups (sizes of groups see Table 1) 
indoor situations (4.0-9.0\%), while all other subgroups (5.9-59.8\%) indicate higher rates of health effects compared to the general population (5.5-11.9\%) (Table 4).

These findings have the following implications:

Self-reported exposure is high. This is a very striking finding in this study. My three hypotheses, that people who read references, that people who prefer fragrancefree products and that people who are fragrance-sensitive or experience any other health effects would reduce their own use of fragrances and avoid exposure by others, proved to be wrong (Fig. 4). A very high number of individuals who describe adverse health effects upon exposure to fragrances seem to expose themselves to fragrances in their direct environment to a similar or even higher extent compared to the general population. Apparently, they make a causal link between fragrances and the health effects observed, but, at the same time, they do not refrain from using these products. This could be regarded as another example for cognitive dissonance at first sight. Additional investigations with detailed questions are needed to understand this unsatisfactory risk behavior. For example, more information about the amounts used could be a puzzle piece in the explanations: It cannot be excluded that survey participants name exposure by other peoples' use more frequently because they have a higher attentiveness and awareness of the presence of fragrances products in the indoor air. This means that it is not certain whether this subjective assessment corresponds to a quantitatively more frequent or higher exposure. However, an increased awareness cannot explain the higher reported rates of own use of fragranced products. The answers given to the questions on own use can be considered as more objective, while answers about other peoples' use depend on the sense of smell and the attention given by survey participants. Furthermore, as the questionnaire does not ask for the quantities applied, it is possible that the actual total exposures are lower compared to the average population, in case survey participants apply smaller amounts of fragranced products and use them less frequently. The survey conducted in Germany, in 2010, described that products which consumers used frequently such as personal care products or cleaning products were considered as less toxic compared to products which were used rarely such as building products [10]. This could also be an explanation for the frequent exposure to fragranced products in the present study, as most of them are used frequently in the general population.

Educational work is a hard task if emotions are strong and knowledge is insufficient. This is also evident in the case of "green", "organic" and "natural" products. The positive attitude toward these trigger words is widespread in the general population [10], although toxicity of "green" and natural products is similar to regular products $[1$, 20]. This uncritical opinion about natural substances can also be explained by the widespread infantilization and naïve view on nature in today's society, especially in the young generation, suitably called "Bambi syndrome" [23]. The survey conducted in Germany in 2010 revealed that people with lower income had a more positive attitude toward products called "natural" and more critical attitude toward chemicals in general, while, surprisingly, the education did not seem to play any role for this attitude [10]. In the present study, there is no correlation of the attitude toward natural fragrances with annual income of the survey participants. It was found that people who thought that natural products are healthier believed in their personal risk perception and supported it by smell, product color, and shape of packaging [10]. They were interested in more information, but only under the condition that it supported their beliefs and was not against them [10]. In our study, more than half of the general population (55.6\%) believe that products with natural fragrance ingredients are healthier than products with synthetic fragrance ingredients (Table 3). Two-thirds (69.2\%) of people who prefer fragrance-free products believe that products with natural fragrance ingredients are healthier (Table 3). Even individuals who know better still believe that those products would be healthier, another example for apparent cognitive dissonance.

\section{Conclusions}

A detailed and decent risk assessment for fragrancecontaining products, which would consider the realistic situation of aggregate exposure and the multitude of potential health effects, would require quantitative data on products ingredients and data on individual use patterns including the personal exposure (amounts used, ventilation, duration of time spent indoor or outdoor, etc.) and data on the multitude of potential health effects induced by single chemicals and chemical mixtures. This is a task that would be extremely demanding. In contrast, the present survey is a straightforward and immediate method to measure actual risk perception in the general public collecting the actual experiences made by users of fragranced products, and thus this survey is able to give a comprehensive representative picture for the present situation in the general population.

Some answers given by various subgroups of the German population seem to represent cognitive dissonances at first sight: Why do fragrance-sensitive persons indicate to expose themselves to even more fragranced products than the general population? Why do many people who are fragrance-sensitive not read the references of products to learn more about fragrance ingredients? Why do nearly all people who say that they would 
prefer fragrance-free products indicate to be exposed to fragrances by their own use? Why do not all fragrancesensitive persons prefer fragrance-free products (but only less than two-thirds)? Why do even half of the people who describe a partial loss of bodily or mental functions due to the exposure to fragrances use fragrances to feel more attractive? Why do people who know that so-called natural, green, and organic fragranced products typically emit hazardous air pollutants still believe that products with natural fragrance ingredients would be healthier? Why do half of the persons who do not use fragrances to feel more attractive apply perfume themselves? People might have their comprehensible reasons to behave like this. For example, cultural habits, unspoken presumed expectations by colleagues or trade-off of positive and negative aspects of fragranced products could make people use fragrances even if they experience adverse health effects. People might consider it so important to apply fragranced products that they ignore or accept the presumed triggers for their illnesses. The results of this survey show that a lot more information about consumers' incentives to use fragranced products is needed to understand their motivations.

\section{Recommendations}

These very complex and important issues merit systematic further analyses:

a. Quantitative descriptions of the cause-effect relationships (which means that objective data are needed as scientific reproducible verification of the self-reported-necessarily subjective-description of the health effects in this survey),

b. Elucidation which concentrations of which chemicals are responsible for which health effect. It is possible that the triggering substances are fragrance ingredients themselves, and it is also possible that substances applied in combination with fragrance ingredients (e.g., solvents or preservatives) induce the reactions or that the effects are due to combinations of various substances [11].

c. Improvement of legal standards following the precautionary principle, such as obligatory declaration of fragrance ingredients and prohibition of the major culprits, not only in cosmetic products, but also in other product groups,

d. Support for medical staff to find the causes for symptoms that have not been linked to fragrance exposure so far,

e. Improvement of risk communication [24] by giving recommendations for consumers to reduce exposure to hazardous substances and hence health effects, f. Analysis of cultural aspects that influence use of and attitude versus fragranced products and comparison with other countries, also outside the EU, and

g. Reduction of exposure by increasing the availability of fragrance-free consumer products and fragrancefree indoor spaces, following the precautionary principle.

In Europe, the compulsory listing of fragrances on the product label applies only to 26 fragrance ingredients in personal care products and washing and cleaning products. There are no regulations for other product categories about the indication of fragrances substances contained. According to the data in this study, a considerable part of the population $(28.3 \%)$ is reading references to obtain more information on fragrances in the product, but reading this information does not seem to be sufficient to lead to a suitable safety behavior. Listing the ingredient names may rather be useful for the subsequent identification of causal allergens present in specific personal care products, which patients bring to the hospital staff. Health effects other than dermal effects are more difficult to link causally to certain exposures. A list of ingredients on product containers is certainly useful, but this study confirms that only a small number of persons are willing to use this information (see also [24]).

This study shows clearly that the present risk communication strategy for fragrance ingredients does not motivate even vulnerable consumers, who observe already health effects, to avoid exposure. On this ground, I assume that further appeals to consumers might not be efficient to improve general health. The elucidations of cause and effect relationships and detailed risk assessments (see recommendations $\mathrm{a}$ and $\mathrm{b}$ above) would be very time-consuming and costly and would not be an immediate help for the large number of persons who report adverse health effects today. Therefore, I rather recommend above all to reduce exposure by omitting potentially harmful substances in products and by increasing the number of fragrance-free products and fragrance-free indoor spaces.

\section{Supplementary information}

Supplementary information accompanies this paper at https://doi. org/10.1186/s12302-020-00311-y.

Additional file 1. SSI methodology.

Additional file 2. Survey methods.

Abbreviations

ESM: Electronic supplementary material; SSI: Survey Sampling International. 


\section{Acknowledgements}

I thank the staff of Dynata (formerly SSI) for their superb work. I also thank Anne Steinemann very much for her excellent work, for the opportunity to add my additional questions to her survey in Germany in 2019 and for ceding me the results for further use. And I thank my student Sabrina Hartmann for her helpful review of this manuscript and the design of the figures.

\section{Authors' contributions}

The author designed the project, wrote the manuscript. The author read and approved the final manuscript.

\section{Funding}

The author did not receive any funding for this research work. The survey was supported by university discretionary research funding. This article belongs to a series of contributions submitted from members of the 'Division of Environmental Chemistry and Ecotoxicology' of the 'German Chemical Society (GDCh)'.

\section{Availability of data and materials}

All data generated or analyzed during this study are included in this published article.

\section{Ethics approval and consent to participate}

All information collected was self-reported by the participants and all responses of the survey participants were anonymous. The demographic information collected did not allow for the identification of any participant of the survey. The research study received ethics approval from the University of Melbourne.

\section{Consent for publication}

Not applicable.

\section{Competing interests}

The author declares that she has no competing interests.

Received: 16 January 2020 Accepted: 14 February 2020

Published online: 26 February 2020

\section{References}

1. Steinemann AC, MacGregor IC, Gordon SM, Gallagher LG, Davis AL, Ribeiro DS, Wallace LA (2011) Fragranced consumer products: chemicals emitted, ingredients unlisted. Environ Impact Assess Rev 31:328-333. https://doi.org/10.1016/j.eiar.2010.08.002

2. Klaschka U, Kolossa-Gehring M (2007) Fragrances in the environment: pleasant odours for nature? Env Sci Poll Res Int 14:44-52. https://doi. org/10.1065/espr2007.01.380

3. Regulation 1223/2009 of the European Parliament and of the Council on Cosmetic Products. Off J Eur Commun. L342: 59, 1-151. http://eur-lex. europa.eu/LexUriServ/LexUriServ.do?uri=OJ:L:2009:342:0059:0209:en: PDF

4. Steinemann A (2016) Fragranced consumer products: exposures and effects from emissions. Air Qual Atmos Health 9:861-866. https://doi. org/10.1007/s11869-016-0442-z

5. Steinemann A (2017) Health and societal effects from exposure to fragranced consumer products. Prev Med Rep 5:45-47. https://doi. org/10.1016/j.pmedr.2016.11.011

6. Steinemann A (2018) Fragranced consumer products: sources of emissions, exposures, and health effects in the UK. Air Qual Atmos Health 11:253-258. https://doi.org/10.1007/s11869-018-0550-z

7. Steinemann A (2018) Exposures and effects from fragranced consumer products in Sweden. Air Qual Atmos Health 11:485-491. https://doi. org/10.1007/s11869-018-0565-5

8. Steinemann A, Klaschka U (2019) Exposures and effects from fragranced consumer products in Germany. Air Qual Atmos Health 12:1399-1404. https://doi.org/10.1007/s11869-019-00770-0
9. Steinemann A (2018) Fragranced consumer products: effects on autistic adults in the United States, Australia, and United Kingdom. Air Qual Atmos Health 11:1137-1142. https://doi.org/10.1007/s11869-018-0625-x

10. Epp A, Hertel R, Böl G-F (2010) Chemie im Alltag: eine repräsentative Befragung deutscher Verbraucherinnen und Verbraucher. Bundesinstitut für Risikobewertung, Berlin https://mobil.bfr.bund.de/cm/350/chemi e_im_alltag.pdf (in German)

11. Wieck S, Olsson O, Kümmerer K, Klaschka U (2018) Fragrance allergens in household detergents. Regul Toxicol Pharmacol 97:163-169. https://doi. org/10.1016/j.yrtph.2018.06.015

12. Klaschka U (2010) Risk management by labelling 26 fragrances?: evaluation of Article 10 (1) of the seventh Amendment (Guideline 2003/15/EC) of the Cosmetic Directive. Int J Hyg Environ Health 213:308-320. https:// doi.org/10.1016/j.ijheh.2010.04.001

13. Schnuch A, Uter W, Lessmann H, Geier J (2015) Risk of sensitization to fragrances estimated on the basis of patch test data and exposure, according to volume used and a sample of 5451 cosmetic products. Flav Fragr J 30:208-217. https://doi.org/10.1002/ffj.3241

14. Schnuch A, Uter W, Geier J, Lessmann H, Frosch PJ (2007) Sensitization to 26 fragrances to be labelled according to current European regulation. Contact Dermatitis 57:1-10. https://doi.org/10.111 1/j.1600-0536.2007.01088.x

15. Uter W, Yazar K, Kratz E-M, Mildau G, Lidén C (2013) Coupled exposure to ingredients of cosmetic products: I Fragrances. Contact Dermatitis 69:335-341. https://doi.org/10.1111/cod.12125

16. Rastogi SC, Heydorn S, Johansen JD, Basketter DA (2001) Fragrance chemicals in domestic and occupational products. Contact Dermatitis 45:221-225. https://doi.org/10.1034/j.1600-0536.2001.450406.x

17. Regulation No 1272/2008 of the European Parliament and of the Council of 16 December 2008 on classification, labelling and packaging of substances and mixtures, amending and repealing Directives 67/548/EEC and 1999/45/EC, and amending Regulation (EC) No 1907/2006. http:// eur-lex.europa.eu/LexUriServ/LexUriServ.do?uri=CELEX:32008R1272 :en:NOT

18. Lysdal SH, Johansen JD (2009) Fragrance contact allergic patients: strategies for use of cosmetic products and perceived impact on life situation. Contact Dermatitis 61:320-324. https://doi.org/10.111 1/j.1600-0536.2009.01626.x

19. Bickers DR, Calow P, Greim HA, Hanifin JM, Rogers AE, Saurat J-H, Glenn Sipes I, Smith RL, Tagami H (2003) The safety assessment of fragrance materials. Reg Tox Pharm 37:218-273. https://doi.org/10.1016/S0273 $-2300(03) 00003-5$

20. Klaschka $U$ (2015) Naturally toxic: natural substances used in personal care products. Environ Sci Eur 27:1. https://doi.org/10.1186/s1230 2-014-0033-2

21. Rozin P, Fischler C, Imada S, Sarubin A, Wrzesniewski A (1999) Attitudes to Food and the Role of Food in Life in the U.S.A., Japan, Flemish Belgium and France: possible Implications for the Diet-Health Debate. Appetite 33:163-180. https://doi.org/10.1006/appe.1999.0244

22. Bello A, Quinn MM, Perry MJ, Milton DK (2009) Characterization of occupational exposures to cleaning products used for common cleaning tasks-a pilot study of hospital cleaners. Environ Health 8:11. https://doi. org/10.1186/1476-069X-8-11

23. Engl A, Risch B (2019) Die Natur als Labor-Chemieunterricht im Freiland. Nachr Chem 67:18-21. https://doi.org/10.1002/nadc.20194083853 (In German)

24. Klaschka U, Rother H-A (2013) 'Read this and be safe!' Comparison of regulatory processes for communicating risks of personal care products to European and South African consumers. Environ Sci Eur 25:30. https:// doi.org/10.1186/2190-4715-25-30

\section{Publisher's Note}

Springer Nature remains neutral with regard to jurisdictional claims in published maps and institutional affiliations. 